\title{
Developing Preservice Teachers' Expertise in Evaluating and Adapting Mathematics Lesson Plans
}

Journal of Special Education Preparation 1(1), 36-46

(C) Morano and Riccomini

Licensed with CC-BY-NC-ND 4.0 License

DOI: 10.33043/JOSEP.1.1.36-46

openjournals.bsu.edu/JOSEP

\section{Stephanie Morano and Paul J. Riccomini}

\begin{abstract}
To provide appropriate and effective instructional supports to students with disabilities, special education preservice teachers require development of expertise in the design and delivery of specially designed lessons. It is critical that special education preservice education programs provide students ample opportunities to learn how to evaluate and adapt lesson plans through the application of the elements of explicit instruction. In this article, we explain how to develop preservice teachers' expertise in the evaluation and adaptation of mathematics lesson plans with the elements of explicitness to better support students with disabilities. The example activity and assignments provided are anchored in the context of a university math methods course and include all necessary materials.
\end{abstract}

\section{Keywords:}

explicit instruction, mathematics, special education teacher preparation

Acquiring foundational mathematics skills and learning to apply those skills is critical to the academic success of all learners and is becoming more important for post school employment opportunities as growth in science, technology, engineering, and mathematics (STEM) careers significantly outpaces growth in non-STEM occupations (U.S. Department of Commerce, 2017). Given the importance of success in mathematics, it is essential that educators provide more effective support for students with disabilities struggling to acquire critical mathematics concepts and skills (Wei et al., 2012; Stevens, et al., 2015). Although gains in mathematics performance have been observed, performance outcomes for students with disabilities are still in need of improvement (NAEP, 2017; Schleicher, 2018). The implications of insufficient math performance for students with disabilities extend well beyond achievement test scores by impacting competitive employment opportunities and competitive wages (U.S. Department of Labor, 2020). Clearly, a need exists to provide more intensive support for students with disabilities to positively impact their mathematics outcomes.

In recent decades, studies investigating mathematics interventions, instructional strategies, and early numeracy development have identified effective practices that can support students in learning mathematics and improve their math outcomes (e.g., Baker et al., 2002;
Clarke et al., 2015; National Mathematics Advisory Panel, 2008; Pellegrini et al., 2021). Although the research base is expansive in terms of math content focus, grade level, disability type, and intervention design, explicit instruction is often the foundation of methods and practices identified as effective. Due to the strength of the evidence in support of explicit mathematics instruction for struggling students, the IES practice guide, Assisting Students Struggling with Mathematics (Gersten et al., 2009), recommends that mathematics intervention instruction should be explicit and systematic.

\section{Explicit Instruction}

Based on a review of the literature where explicit instruction was the primary focus of intervention or discussion, Hughes et al. (2017) define explicit instruction as follows:

Explicit instruction is a group of research-supported instructional behaviors used to design and deliver instruction that provides needed supports for successful learning through clarity of language and purpose, and reduction of cognitive load. It promotes active student engagement by requiring frequent and varied responses followed by appropriate affirmative and corrective feedback, and assists long-term retention through use of purposeful practice strategies (p.143).

In addition to creating this definition, Hughes et al. identified five essential components of explicit in- 
struction (present in at least $75 \%$ of the 68 publications reviewed) and seven additional common components (present in at least $50 \%$ of reviewed publications). The five essential components include: (a) segment complex skills; (b) draw student attention to important features of the content through modeling/think-alouds; (c) promote successful engagement by using systematically faded supports/prompts; (d) provide opportunities for students to respond and receive feedback; and (e) create purposeful practice opportunities. These five essential components of explicit instruction, as well as the seven common components, are all included in Archer and Hughes' (2011) previously published list of 16 elements of explicit instruction (see Figure 1).

Figure 1. Principles and Elements of Explicit Instruction

Principles of Explicit Instruction

1. Optimize engaged time/time on task.

2. Promote high levels of success.

3. Increase content coverage.

4. Have students spend more time in instructional groups.

5. Scaffold instruction

6. Address different forms of knowledge.

\section{Elements of Explicit Instruction}

1. Focus on critical content. ${ }^{b}$

2. Sequence skills logically. ${ }^{\mathrm{b}}$

3. Break down complex skills and strategies into smaller instructional units. ${ }^{a}$

4. Design organized and focused lessons.

5. Begin lessons with a clear statement of the lesson's goals and your expectations. ${ }^{\mathrm{b}}$

6. Review prior skills and knowledge before beginning instruction. ${ }^{b}$

7. Provide step-by-step demonstrations. ${ }^{a}$

8. Use clear and concise language.

9. Provide an adequate range of examples and non-examples. ${ }^{b}$

10. Provide guided and supported practice. ${ }^{a}$

11. Require frequent responses. ${ }^{a}$

12. Monitor student performance closely.

13. Provide immediate affirmative and corrective feedback. ${ }^{\mathrm{a}}$

14. Deliver the lesson at a brisk pace. ${ }^{\mathrm{b}}$

15. Help students organize knowledge. ${ }^{\mathrm{b}}$
16. Provide distributed and cumulative practice. ${ }^{\mathrm{a}}$

Note. Lists of 6 principles and 16 elements of explicit instruction are sourced from Archer and Hughes (2011). a Essential elements of explicit instruction as identified by Hughes et al. (2017). ' Common elements of explicit instruction as identified by Hughes et al. (2017).

In addition to its inclusion as a key recommendation in the IES practice guide, Assisting Students Struggling with Mathematics (Gersten et al., 2009), explicit instruction has been identified as one of 22 High Leverage Practices (HLPs) that are critical for all special education teachers entering the profession to learn (Windschitl et al., 2012). Further, the Council for Exceptional Children's Initial Preparation Standard 5: Instructional Planning and Strategies requires beginning special education professionals to develop expertise in evidenced-based instructional strategies, including explicit instruction (CEC, 2021). Table 1 contains a list of resources related to explicit instruction.

Explicit instruction is the keystone of the design and delivery of specially designed instruction (Riccomini et al., 2017); and for many students with disabilities, explicit instruction in mathematics is critical for learning (Doabler \& Fien, 2013). In effect, applying the principles and elements of explicit instruction when developing new lesson plans and when adapting (non-explicit) lesson plans is a primary responsibility for educators supporting students with disabilities, regardless of classroom setting, disability category, grade level, or mathematical content. Further, because many special education teachers support students with disabilities in general education classrooms (e.g., co-teaching, pushin support), where instruction is organized around a mathematics curriculum that has been adopted by their school or district, they are responsible for evaluating and adapting the curriculum lessons to better support their students.

Although most mathematics curricula attempt to address the learning needs of struggling students, they are not designed specifically to support students with disabilities (Doabler et al., 2012) or English learners with disabilities (Doabler et al., 2016). This often means that special educators must adapt lessons to make them more explicit, and therefore more effective for their students (Sayeski \& Paulsen, 2010). As a result, it is necessary for preservice teachers (PSTs) to learn to deliver explicit mathematics instruction, to be able to identify 
Table 1. Explicit Instruction Resources for Math

\section{Resource}

Archer \& Hughes, 2011.

IES Practice Guides

\section{CEEDAR Center}

National Center on Intensive Intervention

Division for Learning Disabilities

Retrieval Practice: The Science of Learning

IRIS Resource Locator

Sayeski, \& Paulsen, 2010.

Woodward, \& Montague, 2002.

Doabler, Nelson, \& Clarke, 2016.

Doabler, Smith, Nelson, Clarke, Berg, \& Fien, 2018.

Doabler \& Fien, 2013.

Kirschner, Sweller, \& Clark, 2006.

Doabler, Strand, Cary, Jungjohann, Clarke, Fien, Baker, Smolkowski, \& Chard, 2012.

\section{Description}

Comprehensive text on explicit instruction and accompanying website: https://explicitinstruction.org/

Young Children: https://ies.ed.gov/ncee/wwc/PracticeGuide/18

Fractions: https://ies.ed.gov/ncee/wwc/PracticeGuide/15

Algebra: https://ies.ed.gov/ncee/wwc/PracticeGuide/20

https://ceedar.education.ufl.edu/hlps/

https://intensiveintervention.org/

https://www.teachingld.org/topics/mathematics/

https://www.retrievalpractice.org/

\section{https://iris.peabody.vanderbilt.edu/}

Mathematics reform curricula and special education: Identifying intersections and implications for practice. Intervention in School and Clinic, 46, 13-21.

Meeting the challenge of mathematics reform for students with LD. The Journal of Special Education, 36, 89-101.

Adapting evidence-based practices to meet the needs of english learners with mathematics difficulties. TEACHING Exceptional Children, 48, 301310.

A guide for evaluating the mathematics programs used by special education teachers. Intervention in School and Clinic, 54, 97-105.

Explicit mathematics instruction: What teachers can do for teaching students with mathematics difficulties. Intervention in School and Clinic, 48, 276-285.

Why minimal guidance during instruction does not work: An analysis of the failure of constructivist, discovery, problem-based, experiential, and inquiry-based teaching. Educational Psychologist, 41, 75-86.

Enhancing core math instruction for students at-risk for mathematics disabilities. TEACHING Exceptional Children, 4, 48-57. the instructional approach of mathematics curricula, and to learn to adapt or revise non-explicit instructional plans using the principles and elements of explicit instruction.

\section{Purpose}

Given the persistent poor math performance and related negative post school outcomes for students with disabilities, it is necessary to reexamine how preservice special education preparation programs prepare their graduates to support students in math (Powell, 2015).
Teaching PSTs to effectively use explicit instruction in mathematics is an important goal and one supported by evidence from math intervention research and special education teacher preparation standards. The remainder of this article provides a detailed description of an activity and assignments the authors use in undergraduate and graduate level special education math methods courses to meet the goal of preparing special education PSTs to provide effective, explicit instruction in mathematics. 
How to Teach PSTs to Evaluate and Adapt

\section{Math Lesson Plans for Explicitness}

This section describes an in-class activity and related independent assignments that are designed to teach PSTs (1) how to evaluate mathematics lesson plans in regard to their explicitness; and (2) how to adapt mathematics lesson plans to make them more explicit and more effective for students with disabilities. Implementing the initial, in-class lesson plan evaluation activity takes 1-2 class sessions and the follow-up lesson plan evaluation and revision assignments span several weeks. The activity and assignments meet key elements of at least two of the Council for Exceptional Children's (CEC's) Initial Preparation Standards related to Curricular Content Knowledge Standard \#3 and Instructional Planning and Strategies Standard \#5 (CEC, 2021). Table 2 contains a check list of CEC key elements addressed in this activity and the follow-up assignments. The activity and assignments are scaffolded so that the initial, in-class lesson plan evaluation activity involves significant guidance from the instructor, while the follow-up assignments allow students to practice these skills with greater independence.

\section{Preparing to Implement the Activity and As- signments}

The initial in-class lesson plan evaluation activity requires that PSTs have some background knowledge about explicit instruction, so initial instruction about explicit instruction prior to implementing the activity is recommended. In the authors' math methods courses, one or two class sessions prior to the in-class lesson evaluation activity are dedicated to: (a) learning about the principles and elements of explicit instruction (see Figure 1); (b) the research support for using explicit instruction to teach math to students with disabilities, and; (c) the differences between explicit math instruction and a more constructivist approach to math instruc- tion, which is currently popular in schools (Sayeski \& Paulsen, 2010) and less effective than explicit math instruction for students with disabilities (e.g., Guilmois et al., 2019; Kroesbergen et al., 2004). Constructivist math instruction can be characterized as an approach in which students must discover or construct essential information for themselves, rather than being presented with essential information and provided with a high degree of instructional guidance (Kirschner et al., 2006). A flow chart that situates the in-class lesson evaluation activity and follow-up assignments within the context of other relevant elements of the authors' math methods courses is provided in Figure 2.

\section{In-Class Activity: Learning to Evaluate Math Lessons for Explicitness}

The in-class lesson evaluation activity takes about two hours to implement. It is possible to complete the activity in one long class session or break it up over two shorter sessions. The procedure and sample materials for implementing the activity are presented below.

\section{Introduce the Lesson Plan Evaluation Checklist}

\section{( 10-15 min.)}

The first step in implementing the in-class lesson plan evaluation activity is introducing the lesson plan evaluation checklist. The checklist (see Figure 3) is designed to evaluate the explicitness of a lesson and was adapted from the five essential components of explicit instruction as described by Hughes et al. (2017) and the Mathematics Program Evaluation Guide designed by Doabler et al. (2018). The checklist includes a column with 10 items that describe important elements of a well-designed explicit mathematics lesson plan; a column in which the user rates each item as missing, insufficient, or sufficient; and a column in which the user can make notes and suggestions for revision or adaptation.

To start the in-class activity, activate students' prior knowledge about explicit instruction by asking them to

Figure 2. Flowchart of Activities and Assignments on Evaluating and Revising Math Lesson Plans

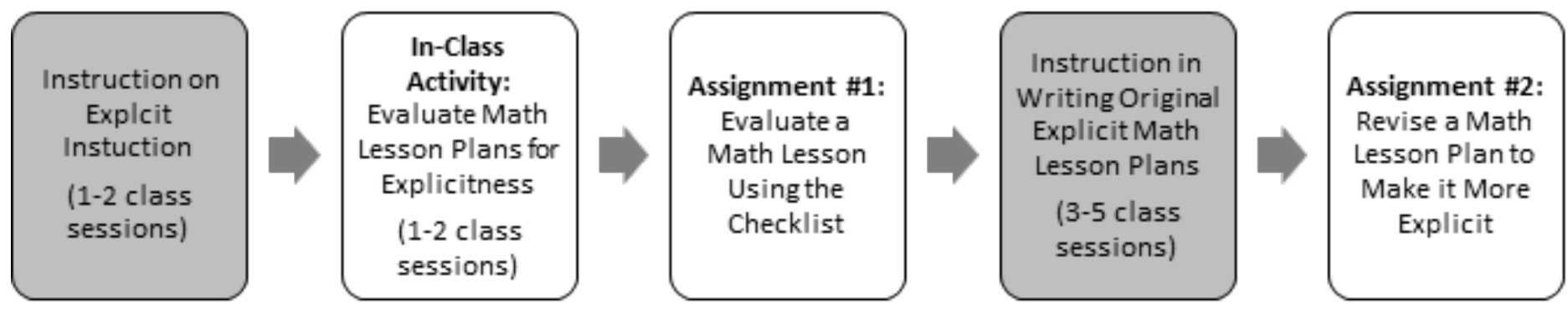

Note. The activities and assignments in white boxes are those described in detail in the how-to section. 
Table 2. CEC Initial Preparation Standards Checklist

\begin{tabular}{ll}
\hline Standard & Key Element Addressed \\
\hline Standard \#3: & $\checkmark \quad$ Beginning special education professionals use knowledge of general and \\
Curricular Content Knowledge & specialized curricula to individualize learning for individuals with exceptional- \\
& ities. \\
& $\checkmark \quad$ ized curricula to make them accessible to individuals with exceptionalities. \\
& $\checkmark \quad$ Beginning special education professionals select, adapt, and use a reper- \\
Standard \#5: & toire of evidence-based instructional strategies to advance learning of indi- \\
& viduals with exceptionalities \\
& $\checkmark \quad$ Beginning special education professionals select, adapt, and use a reper- \\
& toire of evidence-based instructional strategies to advance learning of indi- \\
& viduals with exceptionalities \\
& $\checkmark \quad$ Beginning special education professionals select, adapt, and use a reper- \\
& toire of evidence-based instructional strategies to advance learning of indi- \\
& viduals with exceptionalities \\
& $\checkmark \quad$ Beginning special education professionals teach to mastery and promote \\
& generalization of learning. \\
& $\checkmark \quad$ Beginning special education professionals teach cross-disciplinary knowl- \\
& edge and skills such as critical thinking and problem solving to individuals \\
with exceptionalities.
\end{tabular}

Note. CEC Initial Preparation Standards: https://exceptionalchildren.org/standards/initial-special-education-

preparation-standards

do a think-pair-share as they try to recall as many as possible of the 16 elements of explicit instruction (Archer \& Hughes, 2011). Write or record the elements as students list them during the share. If the share doesn't yield all 16 elements, fill in the gaps before moving on. Next, project the lesson plan evaluation checklist and give students access to their own copies. Review each of the 10 checklist items with the class and discuss how they relate to the elements of explicit instruction.

\section{Have Students Read an Explicit Math Lesson Plan ( 10 min.)}

The next step is to have students read an explicit lesson plan. The authors use the lesson plan on the order of operations published on pp.41-43 in the Archer \& Hughes (2011) text, Explicit Instruction: Effective and Efficient Teaching (included in supplemental files with permission). Instructors can give students approximately 10 minutes to read the lesson plan in class or assign the reading to be completed before class.

\section{Lead the Class in Using the Checklist to}

\section{Evaluate the Explicit Lesson ( 30 min.)}

After students have reviewed the explicit lesson plan, lead the class in using the checklist to evaluate the plan. The Archer \& Hughes (2011) lesson plan on the order of operations (or any well-designed explicit math lesson plan) will earn scores of 3 (sufficient) for most, if not all, of the 10 items on the checklist. Starting this activity by using the checklist to evaluate a strong, explicit math lesson (like the Archer \& Hughes lesson) will help to illustrate high-quality examples of each checklist item in action. As discussed, students should have some prior knowledge about explicit instruction before engaging in this activity but learning to recognize how the explicit instruction checklist items take shape in a real lesson will deepen their understanding of what explicit instruction looks like in practice. While working through the checklist, use guided questioning to involve students in the evaluation process. For example, when assessing item 2 (on warm-up/review activities), ask: "What skills or concepts does the review 
Figure 3. Mathematics Lesson Plan Evaluation Checklist

Mathematics Lesson Plan Evaluation Checklist

\begin{tabular}{|l|l|l|}
\hline Lesson: & & \\
\hline Grade Level: & & \\
\hline Standard(s): & & \\
\hline Objective(s): & $\begin{array}{l}\text { Rating } 123 \\
1=\text { missing } \\
2=\text { insufficient } \\
3=\text { sufficient } \\
\text { N/A }\end{array}$ & $\begin{array}{l}\text { Notes and Suggestions for } \\
\text { Revision/Adaptation }\end{array}$ \\
\hline Does the lesson include... & \\
\hline
\end{tabular}

\section{A clear teacher statement about lesson objectives?}

2. Warm-up/review activities that assess student knowledge of critical pre-skills and activate relevant background knowledge?

\section{Modeling $w /$ think aloud?}

The lesson provides specific and sufficient guidelines for teacher modeling.

*The teacher shows and tells students how to meet a learning objective (i.e., provides clear, step-by-step demonstrations) using clear, concise, mathematically accurate language.

\section{Segmentation of complex skills?}

The lesson breaks a complex skill or strategy into smaller instructional units.

\section{Sufficient and appropriate instructional examples that are appropri-} ately sequenced and scaffolded?

\section{Explicit instruction ore review of key mathematics vocabulary terms} using precise, student-friendly definitions?

\section{Systematically faded supports?}

The lesson promotes successful engagement by providing systematically scaffolded practice opportunities.

Initial practice opportunities are heavily supported; then based on students' response, supports are gradually faded to release responsibility and increase student independence.

8. Many opportunities for students to respond with feedback AND opportunities for student verbalizations?

\section{Purposeful practice?}

The lesson provides practice opportunities that align with learning objectives. Practice is distributed and cumulative.

Practice may provide opportunities to use concrete manipulatives and/ or visual representations to model math skills/concepts.

10. Correction procedures or guidelines to address student misconceptions?

Final Evaluation:

Rating total ( 30 = highest possible score)

Final Notes/

Comments: 
or warm-up cover?" "Are these skills and concepts important prerequisites for the objective(s) of the lesson?"

A master version of a completed checklist for the Archer \& Hughes lesson is included in the supplemental files. This completed checklist can be used as a resource for leading the class discussion. It is also helpful to give students their own copy of the master checklist at the end of the activity to keep as a reference. After evaluating the explicit lesson as a whole group, break for a few minutes or until the next class session.

\section{Have Students Read a Constructivist Math}

\section{Lesson Plan ( 10 min.)}

After using the checklist to evaluate a strong example of an explicit lesson, the next step in the activity is to use the checklist to evaluate a non-example of explicit math instruction. Begin this part of the activity by having students read a non-explicit math lesson plan. Assign the reading prior to class to save time if necessary. In this example, the non-explicit, constructivist lesson is a lesson on the order of operations from the Eureka Math/EngageNY mathematics curriculum (Lesson 6: The Order of Operations, Great Minds, 2015; lesson included in supplemental files). The lesson plan is the $6^{\text {th }}$ lesson from the $4^{\text {th }}$ module in the $6^{\text {th }}$ grade math curriculum and is freely available online under a Creative Commons license. This lesson uses an approach to mathematics instruction that is more constructivist than explicit, and while it includes some elements on the explicit evaluation checklist, many elements are 'missing' or 'insufficient.' This lesson provides a good contrast to the explicit Archer and Hughes (2011) lesson because it teaches similar content and targets similar learning objectives, but it takes a different pedagogical approach and would need to be adapted to be used effectively with struggling mathematics students.

\section{Break Students into Small Groups to Evaluate the Constructivist Lesson ( 30 min.)}

After students read the constructivist lesson, break the class into small groups to evaluate the lesson using the checklist. Give pairs or small groups 5-10 minutes at a time to work, then come together as a whole group to review one or two evaluation checklist items at a time. After whole group review, return to pair or group work and repeat this process until students complete their evaluation checklists. As with the explicit lesson, a master version of a completed checklist for the Eureka Math/EngageNY lesson is available in the supple- mental files for use as a resource during the activity and to give to students as a reference once the activity is complete.

\section{Discuss Differences Between the Explicit and the Constructivist Lessons ( 5-10 min.)}

After students have worked to complete an evaluation checklist for one explicit math lesson and one constructivist math lesson, close the in-class activity by leading a whole group discussion focused on noting the greatest differences between the two lessons. Guide this discussion using questioning. For example, ask: "Which checklist items (i.e., elements of explicit instruction) did both lessons include sufficiently?" "Where is there a big discrepancy in explicitness between the two lessons?" "How does the discrepancy reflect the difference between explicit and constructivist teaching philosophies?" For the example lessons used here, the authors like to highlight the differences present in teacher modeling and practice opportunities (see a side-by-side comparison of these checklist items in Figure 4) and discuss the impact these differences are likely to have on mathematics learning for students with disabilities.

\section{Follow-up Assignments: Evaluating and Re- vising Mathematics Lesson Plans}

After completing the initial, in-class lesson plan evaluation activity, have students complete an independent lesson evaluation for a new lesson of their choice; then, several weeks later (after instruction focused on writing original explicit math lesson plans), assign students to revise the lesson they evaluated to make it more explicit and effective for students with disabilities. These two assignments allow students to practice the critical skills of evaluating and adapting lesson plans. More detailed information about both of the assignments is provided below.

\section{Assign Students to Evaluate Another Lesson Plan Independently Using the Checklist}

For the independent lesson plan evaluation assignment, allow students to select a mathematics lesson plan at the grade level they wish to teach or covering math content of particular interest to them. The authors recommend encouraging students to select a math lesson plan published by their state Department of Education, the National Council for Teachers' of Mathematics, Eureka Math/EngageNY, or from the curriculum in 


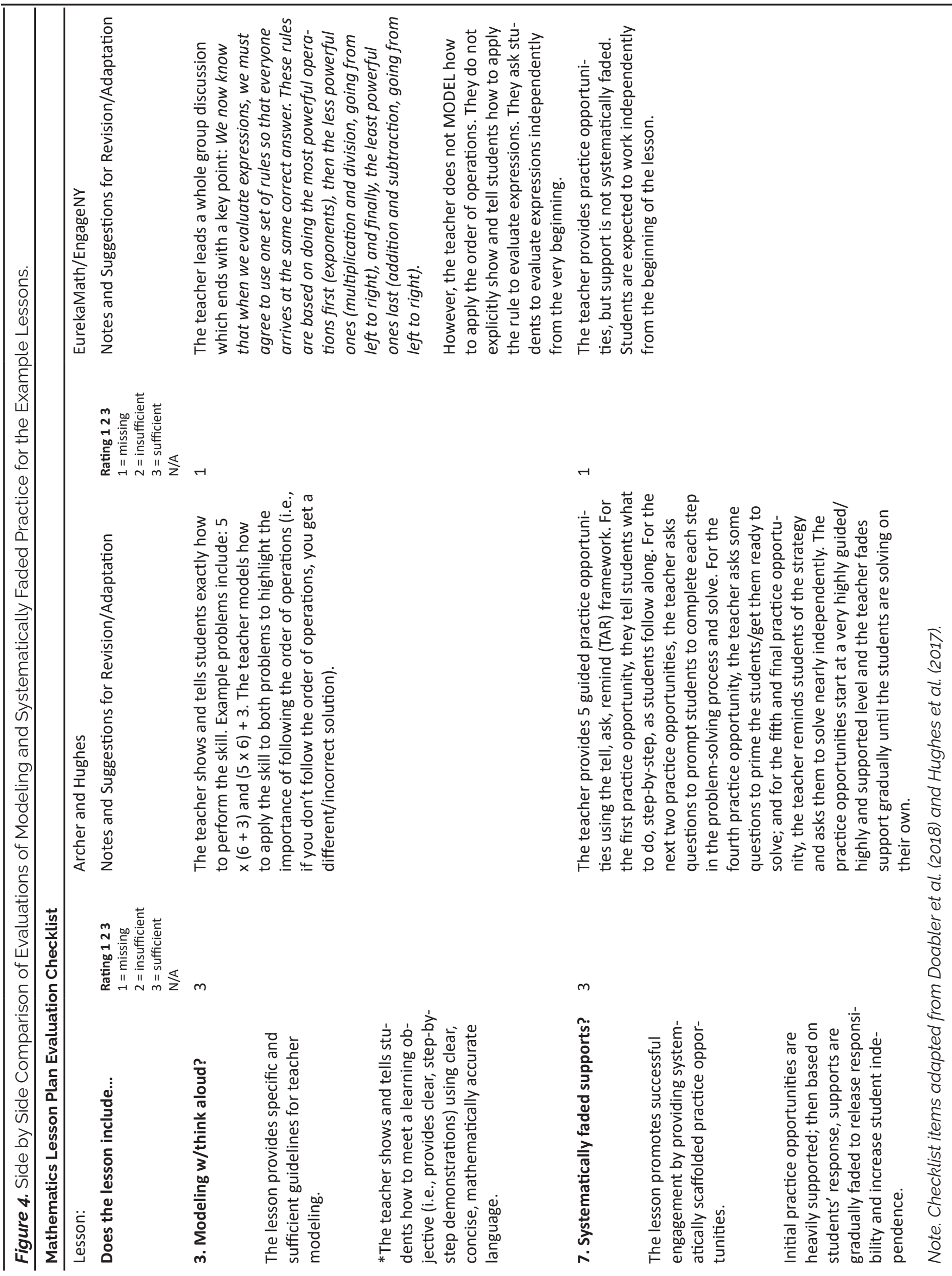


use at the site of their current field experience, school placement, or teaching job. Lessons that include scripting work best for this activity. Allowing students to select a lesson plan can increase engagement with the assignment. Students should submit a copy of the lesson plan they select along with their completed evaluation checklist. Review the students' evaluations of the lessons and provide feedback.

\section{Assign Students to Revise the Lesson they Evaluated to Make it More Explicit.}

The authors typically wait several weeks after students have submitted their independent lesson plan evaluation before assigning the lesson plan revision assignment. In the interim, authors spend several class sessions teaching students to write explicit mathematics lesson plans of their own. By waiting to assign the lesson plan revision assignment until students have had the experience of writing explicit mathematics lessons independently, we ensure that they have all of the skills necessary to effectively adapt a lesson that does not adhere to an explicit framework.

To complete the lesson revision assignment, students first review the lesson evaluation they completed several weeks prior. Next, they use the knowledge and skills they have been honing over the course of the semester to revise or adapt the lesson to make it more explicit. For the lesson revision assignment, ask students to add notes about their ideas for revision to the evaluation checklist they submitted previously, then to write up a brief narrative that explains the revisions they would make and the rationale for those changes. Other options include asking students to rewrite the lesson with their revisions included, or to 'mark-up' a copy of the original lesson by hand or by using a .pdf or document editor. Students can note where they would make additions, cross out lesson elements that they would eliminate, draw arrows to show how they would rearrange lesson activities, and so on. The revised lesson should include the elements of an explicit lesson. Review the updated evaluation checklists and narratives (or revised or annotated lesson plans) that students submit and provide feedback.

\section{Limitations and Potential Roadblocks}

In the authors' experience, the described activities and assignments have a meaningful impact on students' ability to recognize the elements of explicit instruction within math lesson plans and to revise non-explicit lesson plans to make them more explicit and more effec- tive for students with disabilities. However, the effects of the described activities have not been tested experimentally. In addition, the described activity requires a significant amount of time to implement and the assignments require a great deal of specific feedback from the instructor. The in-class activity takes at least one class session but could take two sessions. It may be challenging for instructors to fit the activity into their semesters, especially for those instructors who teach methods courses spanning several different content areas (e.g., math and science; or reading, writing, and math).

In addition, it is important to give specific, detailed feedback on the independent evaluation assignment and on the independent revision assignment, because feedback is an effective tool for closing the gap between students' current performance and desired performance (Archer \& Hughes, 2011, p.175). In order to give meaningful feedback, instructors must read the lesson that students have selected and assess the students' evaluation and recommendations for revision against their own standards. One idea for reducing the amount of time it takes to provide feedback is to preselect the lesson that students will independently evaluate and revise. Then, the instructor can create a master evaluation checklist and a master revised lesson plan to grade all student work against. Instructors could even provide these resources to students to assess and revise their own work. The drawback to this solution is that it removes student choice in the assignment.

\section{Summary}

As faculty in special education teacher preparation programs, it is our responsibility to develop our students' expertise in using evidence-based practices, so they can provide effective instruction and help students with disabilities experience academic and social success. The CEC's initial preparation standards (CEC, 2021) and mathematics instruction guidance documents (Gersten et al., 2009; NMAP, 2008) identify explicit instruction as a crucial practice in mathematics instruction for students with (and without) disabilities, so teaching our PSTs to implement explicit mathematics instruction in our math (or content) methods courses is an important course outcome. Special education teacher trainees must learn to write explicit lesson plans, but because many students with disabilities receive their mathematics instruction in general education classrooms that make use of non-explicit curricula (Sayeski \& Paulsen, 2010), trainees must also learn to 
adapt non-explicit math curriculum to make it more explicit and more effective for students with disabilities. The activity and assignments we present in this article are useful instructional tools that can help prepare special educators with the knowledge and skills to help students with disabilities succeed in math.

\section{References}

Archer, A. L., \& Hughes, C. A. (2011). Explicit instruction: Effective and efficient teaching. New York, NY: Guilford Press.

Baker, S., Gersten, R., \& Lee, D. S. (2002). A synthesis of empirical research on teaching mathematics to low-achieving students. The Elementary School Journal, 103(1), 51-73. https://doi. org/10.1086/499715

Clarke, B., Baker, S., Smolkowski, K., Doabler, C. T., Cary, M. S., \& Fien, H. (2015). Investigating the efficacy of a core kindergarten mathematics curriculum to improve student mathematics learning outcomes. Journal of Research on Educational Effectiveness, 8(3), 303-324. https://doi.org/10.10 80/19345747.2014.980021

Council for Exceptional Children (2015). What every special educator must know: Professional Ethics and Standards. Arlington, VA: CEC. Retrieved March 22, 2021 from https://exceptionalchildren. org/sites/default/files/2020 07/Initial Preparation Standards.pdf

Doabler, C. T., Cary, M. S., Jungjohann, K., Clarke, B., Fine, H., Baker, S., Smolkowski, K., \& Chard, D. (2012). Enhancing core math instruction for students at-risk for mathematics disabilities. TEACHING Exceptional Children, 44(4), 48-57. https://doi.org/10.1177/004005991204400405

Doabler, C. T., \& Fien, H. (2013). Explicit mathematics instruction: What teachers can do for teaching students with mathematics difficulties. Intervention in School and Clinic, 48(5), 276-285. https:// doi.org/10.1177/1053451212473151

Doabler, C. T., Smith, J. L., Nelson, N. J., Clarke, B., Berg, T., \& Fine, H. (2018). A guide forevaluating the mathematics programs used by special education teachers. Intervention in School and Clinic, 54(2), 97-105. https://doi. org/10.1177/1053451218765253

Gersten, R., Beckmann, S., Clarke, B., Foegen, A., Marsh, L., Star, J. R., \& Witzel, B. (2009).
Assisting students struggling with mathematics:

Response to Intervention (RtI) for elementary and middle schools (NCEE 2009-4060). Washington, DC: National Center for Education Evaluation and Regional Assistance, Institute of Education Sciences, U.S. Department of Education. Retrieved March 22, 2021 from https://ies.ed.gov/ ncee/wwc/PracticeGuides

Guilmois, C., Popa-Roch, M., Clément, C., Bissonnette, S., \& Troadec, B. (2019). Effective numeracy educational interventions for students from disadvantaged social background: A comparison of two teaching methods. Educational Research and Evaluation, 25(7-8), 336-356. https://doi.org/ 10.1080/13803611.2020.1830119

Hughes, C. A., Morris, J. R., Therrien, W. J., \& Benson, S. K. (2017). Explicit instruction: Historical and contemporary contexts. Learning Disabilities Research \& Practice, 32(3), 140-148. https://doi. org/10.1111/ldrp.12142

Hughes, C. A., Riccomini, P. J., \& Morris, J.R. (2019). Use explicit instruction. In J. McLeskey, L. Maheady, B. Billingsley, M. Brownell, \& T. Lewis (Eds.), High leverage practices for inclusive classrooms (pp.215-236) New York: Routledge.

Kirschner, P. A., Sweller, J., \& Clark, R. E. (2006). Why minimal guidance during instruction does not work: An analysis of the failure of constructivist, discovery, problem-based, experiential, and inquiry-based teaching. Educational Psychologist, 41(2), 75-86. https://doi.org/10.1207/ s15326985ep4102 1

Kroesbergen, E. H. (2004). Effectiveness of explicit and constructivist mathematics instruction for low-achieving students in the Netherlands. The Elementary School Journal, 104(3), 233-251. https://doi.org/10.1086/499751

Lesson 6: The Order of Operations [lesson plan]. (2015). Great Minds. Retrieved March 17, 2020, from https://www.engageny.org/resource/grade6-mathematics-module-4-topic-b-lesson-6/ file/43556

National Center for Education Statistics. (2017). The Nation's Report Card. Mathematics National Assessment of Educational Progress: National student group scores and score gaps at Grade 8. National Center for Education Statistics. Retrieved March 22, 2021 from https://www.nationsreportcard.gov/math 2017/nation/gaps/?grade $=8$ 
Pellegrini, M., Lake, C., Neitzel, A., \& Slavin, R. E. (2021). Effective programs in elementarymathematics: A meta-analysis. AERA Open, 7, 1-29. https://doi.org/10.1177/2332858420986211

Powell, S. R. (2015). Connecting evidence-based practice with implementation opportunities in special education mathematics preparation. Intervention in School and Clinic, 51(2), 90-96. https://doi. org/10.1177/1053451215579269

Riccomini, P. J., Morano, S., \& Hughes, C. A. (2017). Big ideas in special education: Specially designed instruction, high-leverage practices, explicit instruction, and intensive instruction. TEACHING Exceptional Children, 50(1), 20-27. https://doi. org/10.1177/0040059917724412

Schleicher, A. (2018). PISA 2018: Insights and interpretations. Organization for Economic Co-operation and Development. Retrieved March 22, 2021 from http://www.oecd.org/pisa/PISA $\% 20$ 2018\%20Insights $\% 20$ and $\% 20$ Interpretations $\% 20$ FINAL \%20PDF.pdf

Stevens, J. J., Schulte, A. C., Elliott, S. N., Nese, J. F. T., \& Tindal, G. (2015). Growth and gaps in mathematics achievement of students with and without disabilities on a statewide achievement test. Journal of School Psychology, 53(1), 45-62. https://doi.org/10.1016/j.jsp.2014.11.001

United States Department of Commerce. (2017). STEM Jobs: 2017 update. Retrieved March 22, 2021 from https://www.commerce.gov/sites/ default/files/migrated/reports/stem-jobs-2017-update.pdf

United States Department of Labor. (2020). Persons with a disability: Labor force Characteristics2020. Retrieved March 22, 2021 from https:// www.bls.gov/news.release/pdf/disabl.pdf

Wei, X., Lenz, K. B., \& Blackorby, J. (2012). Math growth trajectories of students with disabilities: Disability category, gender, racial, and socioeconomic status differences from ages 7 to 17 . Remedial and Special Education, 34(3), 154-165. https://doi.org/10.1177/0741932512448253

Windschitl, M., Thompson, J., Braaten, M., \& Stroupe, D. (2012). Proposing a core set of instructional practices and tools for teachers of science. Science Education, 96(5), 878-903. https://doi. org/10.1002/sce. 21027

\section{About the Authors}

\section{Stephanie Morano}

Stephanie Morano, Ph.D. is an assistant professor in special education at the University of Virginia's School of Education and Human Development. Dr. Morano's research investigates math interventions for students with disabilities and approaches to training special education teachers to provide effective mathematics instruction.

\section{Paul J. Riccomini}

Paul Riccomini, Ph.D. is an associate professor of Special Education at the Pennsylvania State University. His current research interests are effective instructional practices and interventions in mathematics for students with high-incidence disabilities. 